\title{
Update on current registries and trials of carotid artery angioplasty and stent placement
}

\author{
Sunit Das, M.D., Bernard R. Bendok, M.D., Christopher C. Getch, M.D., \\ Issam A. AWAd, M.D., AND H. Hunt BAtJer, M.D. \\ Department of Neurological Surgery, The Feinberg School of Medicine, Northwestern University, \\ Chicago, Illinois
}

\begin{abstract}
Stroke remains the leading cause of disability in adults and the third leading cause of death in the US. Carotid artery (CA) occlusive disease is the primary pathophysiological source of 10 to $20 \%$ of all strokes. Carotid endarterectomy (CEA) has been shown to reduce the risk of stroke in patients with both symptomatic and asymptomatic extracranial CA stenosis. Carotid artery angioplasty and stent placement has recently emerged as an alternative to CEA for primary and secondary prevention of stroke related to CA stenosis. With the advent of the embolic protection device, the safety of CA angioplasty and stent placement has approached, if not surpassed, that of CEA. In particular, the former has come to be considered as a first-line therapy in the management of CA stenotic disease in individuals at high risk for complications related to surgical intervention. Preliminary data from multiple registries have demonstrated that CA angioplasty and stent placement is an effective means of treating CA stenosis. The results of the Stenting and Angioplasty with Protection in Patients at High Risk for Endarterectomy trial have demonstrated that this modality has a significant role in the management of CA disease in symptomatic and asymptomatic patients with risk factors for high rates of surgery-related morbidity or mortality. With the completion of the Carotid Revascularization Endarterectomy versus Stent Trial, the role of CA angioplasty and stent placement in the prevention of stroke in all individuals with significant CA stenosis should be better demarcated. This treatment modality promises to assume a central role in stroke prophylaxis in patients with CA disease who are at high risk for complications related to surgery.
\end{abstract}

\author{
KEY WORDS • stroke • carotid artery angioplasty and stent placement • \\ carotid endarterectomy $\bullet$ high-risk patient
}

\section{OVERVIEW}

Stroke remains the leading cause of disability in adults and the third leading cause of death in the US. ${ }^{16}$ Carotid artery occlusive disease is the primary pathophysiological source of 10 to $20 \%$ of all strokes. ${ }^{15}$ In fact, the risk of a first or recurrent stroke has been found to increase with the degree of severity of the CA stenosis, although a linear relationship between degree of stenosis and risk of stroke has not been demonstrated. ${ }^{20}$

\section{Surgical Options}

The use of CEA has been shown to reduce stroke risk in

Abbreviations used in this paper: ACAS = Asymptomatic Carotid Atherosclerosis Study; ACST = Asymptomatic Carotid Surgery Trial; $\mathrm{CA}=$ carotid artery; CAVATAS $=$ Carotid and Vertebral Artery Transluminal Angioplasty Study; CEA = carotid endarterectomy; CREST = Carotid Revascularization Endarterectomy versus Stent Trial; ECST = European Carotid Surgery Trial; EVA-3S = Endarterectomy Versus Angioplasty in Patients With Severe Carotid Stenosis Study; MI = myocardial infarction; NASCET = North American Symptomatic Carotid Endarterectomy Trial; SAPPHIRE = Stenting and Angioplasty with Protection in Patients at High Risk for Endarterectomy; SPACE = Stent-Protected Percutaneous Angioplasty of the Carotid versus Endarterectomy; TIA = transient ischemic attack. patients with both symptomatic and asymptomatic extracranial CA stenosis. Carotid artery angioplasty and stent placement has recently emerged as an alternative to CEA for primary and secondary prevention of stroke related to CA stenosis. Although initial outcome studies indicated higher morbidity and mortality rates for stent placement than is considered acceptable for CEA, the development of new stent technologies and the advent of embolic protection strategies in CA angioplasty and stent placement have improved procedural safety and clinical outcomes. We will briefly review evidence demonstrating the efficacy of CEA in the management of stroke, and discuss new and evolving evidence that CA angioplasty and stent placement may also have a significant role in primary and secondary stroke prevention.

\section{Effectiveness of CEA}

In many patients with CA occlusive disease, CEA is considered the surgical treatment of choice for stroke prevention. The superiority of CEA over medical therapy in the management of symptomatic and asymptomatic CA stenosis has been established in four randomized trials (Table 1): the NASCET, the ECST, the ACAS, and the European ACST.

Findings in the NASCET demonstrated the superior- 
ity of CEA combined with medical therapy over medical management alone for symptomatic patients with CA stenosis of $70 \%$ or more, as measured by conventional angiography. ${ }^{13}$ In these patients, CEA reduced the 2-year risk of ipsilateral stroke from $26 \%$ in the medical group to $9 \%$ in the surgical group, yielding an absolute risk reduction of $17 \%$. A $5.8 \%$ incidence of perioperative stroke or death was reported for patients in the surgical arm. In addition, a smaller but clinically significant risk reduction was seen in patients with 50 to $69 \%$ stenosis, especially men with hemispheric TIAs or minor stroke.

Findings in the ECST confirmed that CEA was statistically superior to medical therapy in reducing risk of future stroke in symptomatic patients with $80 \%$ or greater CA stenosis. ${ }^{7}$ Because the extent of stenoses was measured differently in the ECST and NASCET, the different stenosis thresholds named in the two studies are likely artifactual. The efficacy of CEA in the prevention of stroke in the ECST was similar to that described in the NASCET (a reduction of the 3-year risk of major stroke or death from $26.5 \%$ in the control group to $14.9 \%$ in the surgical group). Interestingly, the 30-day incidence of stroke and death in the ECST was found to be higher in particular subgroups of the study population; specifically, in women $(10.6 \%)$, in patients with $180 \mathrm{~mm} \mathrm{Hg}$ or greater systolic pressure $(12.3 \%)$, and in patients with peripheral vascular disease (12.3\%).

The ACAS trial extended the bounds of CEA by comparing surgical management with medical therapy in asymptomatic patients. Researchers in this study found that patients with CA stenosis of $60 \%$ or greater had better outcomes post-CEA compared with those who received medical treatment alone, with a reduction in stroke incidence at 5 years from $11 \%$ in the medical arm to $5.1 \%$ in patients who underwent surgery. ${ }^{8}$ There was only a $2.3 \%$ risk of perioperative stroke and death associated with CEA in this study, and half of this risk was associ- ated with angiography. The recent ACST confirmed the benefit of CEA in patients with asymptomatic severe stenoses, showing for the first time that CEA cut the risk of fatal stroke in half over 5 years. ${ }^{9}$ In both the ACAS and ACST, an extremely low perioperative stroke rate was achieved, without which there would be no benefit from surgical management of asymptomatic CA stenoses.

\section{High-Risk Patients: a Role for CA Angioplasty and Stent Placement?}

Whereas the CEA trials clearly demonstrated the benefits of this modality over medical management in the treatment of CA stenosis, the stringent eligibility requirements used in these studies excluded many patients at considerable risk for stroke from receiving surgical therapy for their disease. Increased rates of perioperative stroke and death have been noted in observational studies reporting outcomes after CEA in certain patient populations (Table 2). ${ }^{1,3,10,18}$ The same holds true in patients with significant medical comorbidities, including those with a history of MI within 30 days of presentation, unstable angina with electrocardiographic changes, angina with two-vessel coronary artery disease, New York Heart Association Class 3 to 4 congestive heart failure, ejection fraction less than $30 \%$, chronic obstructive lung disease with less than $30 \%$ of predicted forced expiratory volume in 1 second, heart surgery required within 30 days, vascular surgery required within 30 days, or age older than 75 years. In addition, anatomical features increasing the risk of perioperative morbidity include high cervical or intrathoracic stenosis, prior ipsilateral CEA, a history of radical neck dissection or neck irradiation, bilateral CA stenoses, contralateral vessel occlusion, prior contralateral CEA resulting in cranial nerve palsy, cervical spine immobility, crescendo or recent TIAs, tandem stenosis, intracranial hypoperfusion, or tracheostomy. In these patients, the risks of surgery and

TABLE 1

Trials examining the efficacy of CEA in stroke prevention*

\begin{tabular}{|c|c|c|c|c|c|}
\hline Trial & Sample Size & Study Population & Treatment & Outcome Analysis & Comment \\
\hline NASCET & 659 & $\begin{array}{l}\text { symptomatic stenosis } \\
\geq 70 \% \text { on DS angiography }\end{array}$ & $\begin{array}{l}\text { CEA vs medical } \\
\text { management }\end{array}$ & $\begin{array}{l}\text { 30-day death/stroke; } \\
2 \text {-yr death/ipsilat } \\
\text { stroke }\end{array}$ & $\begin{array}{l}\text { periop incidence of stroke/ } \\
\text { death w/ CEA, 5.8\%; 2- } \\
\text { yr incidence of ipsilat } \\
\text { stroke/death: medical } \\
\text { arm, 26\%, CEA arm, } 9 \%\end{array}$ \\
\hline ECST & 3008 & $\begin{array}{l}\text { symptomatic stenosis } \\
\geq 70 \% \text { on DS angiography }\end{array}$ & $\begin{array}{l}\text { CEA vs medical } \\
\text { management }\end{array}$ & $\begin{array}{l}\text { 30-day death/stroke; } \\
\text { 3-yr death/ipsilat } \\
\text { stroke }\end{array}$ & $\begin{array}{l}\text { periop incidence of stroke/ } \\
\text { death w/ CEA, } 6.8 \% ; 3- \\
\text { yr incidence of ipsilat } \\
\text { stroke/death: medical } \\
\text { arm, } 26.5 \% \text {, CEA arm, } 14.9 \%\end{array}$ \\
\hline ACAS & 1662 & $\begin{array}{l}\text { asymptomatic CA stenosis } \\
\geq 60 \% \text { on DS angiography } \\
\text { or Doppler US }\end{array}$ & $\begin{array}{l}\text { CEA vs medical } \\
\text { management }\end{array}$ & $\begin{array}{l}\text { 30-day death/stroke; } \\
\text { 5-yr death/ipsilat } \\
\text { stroke }\end{array}$ & $\begin{array}{l}\text { periop incidence of stroke/ } \\
\text { death w/ CEA, } 2.3 \% ; 5-\mathrm{yr} \\
\text { incidence of ipsilat stroke/ } \\
\text { death: medical arm, } 11 \% \text {, } \\
\text { CEA arm, } 5.1 \%\end{array}$ \\
\hline ACST & 3120 & $\begin{array}{l}\text { asymptomatic CA stenosis } \\
\geq 60 \% \text { by Doppler US }\end{array}$ & $\begin{array}{l}\text { immediate vs } \\
\text { deferred CEA }\end{array}$ & $\begin{array}{l}\text { 30-day death/stroke/ } \\
\text { MI; 5-yr ipsilat } \\
\text { CA territory stroke }\end{array}$ & $\begin{array}{l}\text { 30-day risk of stroke or death } \\
\text { post-CEA, } 3.1 \% ; 5 \text {-yr risk of } \\
\text { stroke, immediate vs deferred } \\
\text { CEA, } 3.8 \% \text { vs } 11 \%\end{array}$ \\
\hline
\end{tabular}

* Comorbid conditions included age older than 80 years, congestive heart failure, severe chronic obstructive pulmonary disease, previous CEA with recurrent stenosis, previous neck irradiation or radical neck dissection, or high cervical or intrathoracic stenosis. Abbreviations: DS = digital subtraction; US = ultrasonography. 
Update on studies of CA angioplasty and stent placement

TABLE 2

High-risk features for patients in whom CEA is considered*

history of MI w/in 30 days

unstable angina $\mathrm{w} /$ electrocardiographic changes

angina $\mathrm{w} / 2$-vessel coronary artery disease

NYHA Class 3-4 congestive heart failure

ejection fraction $<30 \%$

chronic obstructive lung disease $\mathrm{w} /<30 \%$ of predicted FEV

heart surgery required w/in 30 days

vascular surgery required $w /$ in 30 days

age $>75$ yrs

high cervical or intrathoracic stenosis

prior ipsilat CEA

history of radical neck dissection or neck irradiation

bilat CA stenoses, contralat occlusion

prior contralat CEA w/ cranial nerve palsy

cervical spine immobility

crescendo or recent TIAs

tandem stenosis

intracranial hypoperfusion

tracheostomy

$* \mathrm{FEV}_{1}=$ forced expiratory volume in 1 second; NYHA = New York Heart Association.

general anesthesia might outweigh the protective benefit afforded them by CEA. Nevertheless, these comorbidities are common among the patient populations at highest risk for stroke.

Since the mid-1990s, CA angioplasty and stent placement has been investigated as an alternative to CEA for treatment of CA stenosis, especially in patients considered to be at high operative risk. Carotid artery angioplasty and stent placement has the theoretical advantage of reducing CA stenosis without the need for general anesthesia and open surgery. Additionally, preliminary data indicate that the use of strategies to protect against cerebral emboli in $\mathrm{CA}$ angioplasty and stent placement may reduce the risk of an embolic shower associated with CA plaque manipulation. Because the procedure is performed with patients in a state of conscious sedation, symptomatic emboli or hypoperfusion in the brain can be recognized and addressed quickly. Carotid artery angioplasty and stent placement also circumvents the technical challenges involved in dissection and exposure of the CA in preparation for CEA in patients with previous neck irradiation or surgery, long CA stenotic lesions, or high bifurcation stenosis, and in patients with short necks.

\section{Current Clinical Trials of CA Angioplasty and Stent Placement}

Multiple trials investigating the efficacy of CA angioplasty and stent placement as a means for primary and secondary stroke prevention are completed or now under way. Most investigators have chosen to look at the efficacy of this procedure as a treatment modality in particular high-risk populations by using the case-control model for their study design (Table 3). Because many of these trials remain in their nascent stages, only preliminary data measuring the safety of CA angioplasty and stent placement (specifically, its association with procedure-related adverse outcomes) have been reported. Many other important trials, however, have been designed specifically to compare the efficacy of CA angioplasty and stent place- ment against that of CEA (Table 4). We will focus in depth on the EVA-3S, the CAVATAS, the SPACE trial, the CREST, and the SAPPHIRE study.

Initial trials examining the efficacy of CA angioplasty and stent placement in the management of CA occlusive disease were complicated by high rates of perioperative stroke thought to be associated with an iatrogenically created atheroembolic shower. ${ }^{17}$ Instrument manipulations and serial balloon dilations across the diseased CA can disrupt the integrity of the atherosclerotic plaque, causing significant release of microemboli into the distal circulation. Though the great majority of microemboli generated by CA manipulation are clinically insignificant, the potential for instigating an embolic stroke continues to be a major concern. After the initial setbacks with CA angioplasty and stent placement, success has been achieved with the aid of embolic protection devices. ${ }^{14}$ The arm of the EVA$3 \mathrm{~S}$ trial in which CA angioplasty and stent placement was performed without embolic protection was terminated prematurely because the 30-day stroke rate was found to be 3.9 times higher than that of the arm in which CA angioplasty and stent placement was performed with cerebral protection. ${ }^{12}$ In the ACCULINK for Revascularization of Carotids in High-Risk Patients trial, investigators found a similar if not as profound decrease in procedurerelated complications, citing a 30-day major adverse event rate (defined as major stroke, MI, or death) of 7.6\% without an embolic protection device compared with $8.6 \%$ with the device, and a 1-year major adverse event rate of $8.3 \%$ with embolic protection compared with $10.2 \%$ without the device. ${ }^{2}$ The Boston Scientific EPI: A Carotid Stent for High-Risk Surgical Patients, the Carotid Artery Revascularization using Boston Scientific EPI FilterWire and EndoTex Stent, and the Medtronic AVE Self-Expanding Carotid Stent System with Distal Protection in the Treatment of Carotid Stenosis trials have demonstrated similar safety profiles for CA angioplasty and stent placement in high-risk patients when an embolic protection device is used. These and many other registries now in the process of enrolling patients promise to offer data quantifying the safety and efficacy of CA angioplasty and stent placement as a tool for stroke protection.

\section{Selected Studies}

The EVA-3S. As mentioned earlier, the EVA-3S was designed to compare the efficacy of CA angioplasty and stent placement with or without an embolic protection device against CEA in secondary prevention of ischemic stroke. Enrollment in the arm of the study in which CA angioplasty and stent placement was performed without embolic protection devices was halted after it was demonstrated that these patients fared worse than their cohorts in the group undergoing CA angioplasty and stent placement with embolic protection. Currently, patients presenting within 4 months of ischemic cerebral or retinal stroke are randomized into the CA angioplasty and stent placement with embolic protection or the CEA arm. Primary end points include death or recurrent stroke within 30 days and at 2 to 4 years; secondary outcomes are MI, TIA, cranial neuropathy, functional status at the end of the study, and degree of restenosis in treated vessels. Recruitment of patients into the EVA-3S is currently ongoing. 
TABLE 3

Registries for CA stent placement in high-risk patients*

\begin{tabular}{|c|c|c|c|c|}
\hline Registry & Sponsor & Stent & EPD & Comments \\
\hline ARCHeR & Guidant & AccuLink & w/ \& w/o AccuNet & $\begin{array}{l}92.7 \% \text { success rate; } 30 \text {-day MAE } 7.6 \% \text { w/o } \\
\text { EPD, } 8.6 \% \text { w/EPD; } 1 \text {-yr MAE } 8.3 \% \text { w/ EPD, } \\
10.2 \% \text { w/o EPD }\end{array}$ \\
\hline BEACH & Boston Scientific & Wallstent, Monorail & FilterWire EX & 30-day MAE of 5.4\%; now in 1-yr FU \\
\hline CABERNET & $\begin{array}{l}\text { Boston Scientific, } \\
\text { EndoTex }\end{array}$ & NexStent & EPI Filter & $\begin{array}{l}\text { preliminary feedback collected, FU results } \\
\text { pending }\end{array}$ \\
\hline CARESS & ISIS & $\begin{array}{l}\text { currently } \\
\text { unspecified }\end{array}$ & $\begin{array}{l}\text { currently } \\
\text { unspecified }\end{array}$ & $\begin{array}{l}\text { Phase II (450 patients) completed, } 30 \text {-day } \\
\text { MAE } 2 \% \text {; currently enrolling to } 3000 \text { patients }\end{array}$ \\
\hline CREATE & ev3 & Protégé & SPIDER & information not provided \\
\hline MAVErIC & Medtronic & Exponent & $\begin{array}{l}\text { PercuSurge } \\
\text { GuardWire Plus }\end{array}$ & 30-day Phase I results: MAE 4\% \\
\hline PASCAL & Medtronic & Exponent & $\begin{array}{l}\text { any approved } \\
\text { device }\end{array}$ & 30-day results: MAE 8\%; now in 1-yr FU \\
\hline SECuRITY & Abbott & Xact stent & $\begin{array}{l}\text { Emboshield rapid } \\
\text { exchange }\end{array}$ & 30-day results: MAE $7.2 \%$ \\
\hline SHELTER & Boston Scientific & Wallstent, Monorail & $\begin{array}{l}\text { PercuSurge } \\
\text { GuardWire Plus }\end{array}$ & $\begin{array}{l}\text { prospective, multicenter study designed to } \\
\text { enroll } 400 \text { patients at } 30 \text { sites }\end{array}$ \\
\hline
\end{tabular}

* ARCHeR = ACCULINK for Revascularization of Carotids in High-Risk Patients; BEACH = Boston Scientific EPI: A Carotid Stenting Trial for High-Risk Surgical Patients; CABERNET = Carotid Artery Revascularization using the Boston Scientific EPI FilterWire EX and EndoTex NexStent; CARESS = Carotid Revascularization using Endarterectomy or Stenting Systems; EPD = embolic protection device; $\mathrm{FU}=$ follow up; $\mathrm{MAE}=$ major adverse event; $\mathrm{MAVEriC}=$ Evaluation of the Medtronic AVE Self-Expanding Carotid Stent System with Distal Protection in the Treatment of Carotid Stenosis; PASCAL = Performance And Safety of the Medtronic AVE Self-Expanding Stent in Treatment of Carotid Artery Lesions; SECURITY = The Registry Study to Evaluate the Neuroshield Bare Wire Cerebral Protection System and X-Act Stent in Patients at High Risk for Carotid Endarterectomy.

The CAVATAS. The CAVATAS was a randomized trial involving 504 patients treated at 24 centers that was designed to compare CEA with CA angioplasty performed with or without stent placement. ${ }^{5}$ Symptomatic and asymptomatic patients with cerebrovascular disease were randomized to receive CA angioplasty or CEA. Primary outcome measures included recurrent procedure-related morbidity, procedure-related death, or stroke, death, or restenosis over a 3-year period. The data analysis demonstrated no difference in survival or stroke risk between the two groups. Patients in the surgical arm were found to have a higher risk of cranial nerve palsy or hematoma; conversely, restenosis rates were higher in the CA angioplasty group. Based on the success of the CAVATAS and the finding of higher rates of restenosis in the CA angioplasty arm, a second prospective, randomized trial named the International Carotid Stenting Study (also known as CAVATAS-2) was designed to compare the risks and benefits of primary CA stent placement with those of conventional CEA in patients at high risk for stroke. Unfortunately, findings in the International Carotid Stenting Study have been limited by poor enrollment. To date, only approximately 300 of the planned 2000 patients have been randomized to the trial.

The SPACE Trial. To compare the safety and prophylactic efficacy of CEA with CA angioplasty and stent placement against stroke in patients with symptomatic CA stenosis, the German Ministry of Science has sponsored the SPACE trial, a prospective, randomized multicenter study with an expected enrollment of 1900 patients. Eligibility for this study was extended to patients with severe CA stenosis ( $\geq 70 \%$ by duplex ultrasonography, $\geq 50 \%$ by NASCET criteria, or $\geq 70 \%$ by ECST criteria) who had experienced amaurosis fugax, a TIA, or mild stroke within 180 days of randomization. Primary outcome mea- sures include the 30-day incidence of ipsilateral cerebrovascular events or death. Secondary outcomes include the 24-month incidence of death or ipsilateral stroke, restenosis of the treated artery, number of technical complications at 6 and 30 days, and stroke in either hemisphere at 30 days and 24 months posttreatment.

The CREST. The success of CA angioplasty and stent placement performed with the aid of embolic protection devices in the management of $\mathrm{CA}$ atherosclerotic disease prompted the National Institute of Neurological Disorders and Stroke to formulate the CREST. The CREST is a randomized clinical study that was initially designed to compare the efficacy of CEA with that of CA angioplasty and stent placement performed with the aid of an embolic protection device in the prevention of stroke, MI, and death within a symptomatic (history of stroke or TIA) population. The primary end points are death, stroke, or MI at 30 days, or ipsilateral stroke within 60 days of the procedure. The trial has involved multiple centers in North America, with the goal of enrolling 2500 patients. After the publication of the results of the ACST, eligibility in the CREST trial was expanded to include asymptomatic patients with evidence of CA stenosis greater than $60 \%$ (by angiography) or $70 \%$ (by duplex ultrasonography). The study is still in the enrollment phase, but promises to provide direct evidence for the role of CA angioplasty and stent placement in primary and secondary stroke prevention.

The SAPPHIRE Study. The SAPPHIRE study is a multicenter randomized clinical trial designed to compare the efficacy of CEA with that of CA angioplasty and stent placement performed with the aid of an embolic protection device in a high-risk population. The study began with the hypothesis that CA angioplasty and stent placement is a modality of treatment for stroke prevention that is less invasive but not inferior to CEA. Enrollment was 
TABLE 4

Trials comparing CA angioplasty and stent placement with CEA*

\begin{tabular}{|c|c|c|c|c|c|c|}
\hline Trial & Sponsor & $\begin{array}{l}\text { Sample } \\
\text { Size } \\
\text { (expected) }\end{array}$ & Study Population & Treatment & Outcome Analysis & Comment \\
\hline SAPPHIRE & $\begin{array}{l}\text { Cordis } \\
\text { Endovascular }\end{array}$ & 334 & $\begin{array}{l}\text { symptomatic stenosis } \\
>50 \% \text {; asymptomatic } \\
\text { stenosis } \geq 80 \% \text {; } \\
\geq 1 \text { comorbid condition } \dagger\end{array}$ & $\begin{array}{l}\text { CAASP using } \\
\text { PRECISE stent } \\
\& \text { Angioguard } \\
\text { EPD vs CEA }\end{array}$ & $\begin{array}{l}\text { 30-day death/ } \\
\text { MI/stroke; } \\
\text { 12-mo death/ } \\
\text { ipsilat stroke }\end{array}$ & $\begin{array}{l}\text { periop incidence of MAE: CAASP } \\
\text { arm, } 4.4 \% \text {; CEA arm, } 9.9 \% \text {; } \\
\text { 1-yr incidence of MAE: CAASP } \\
\text { arm, } 12 \% \text {; CEA arm, } 20.1 \%\end{array}$ \\
\hline CREST & NINDS & 2500 & $\begin{array}{l}\text { age } 18-80 \text { yrs; } \\
\text { symptomatic CA stenosis } \\
\geq 50 \% \text { on angiography or } \\
\geq 70 \% \text { on Doppler US }\end{array}$ & $\begin{array}{l}\text { CAASP w/ EPD } \\
\text { vs CEA }\end{array}$ & $\begin{array}{l}\text { 30-day death/ } \\
\text { MI/stroke; } \\
\text { 60-day ipsilat } \\
\text { stroke }\end{array}$ & $\begin{array}{l}\text { in progress, } \geq 1600 \text { patients } \\
\text { currently enrolled }\end{array}$ \\
\hline ICSS & UKSA & 2000 & $\begin{array}{l}\text { symptomatic CA stenosis } \\
\geq 70 \% \text { \& age } \geq 40 \text { yrs }\end{array}$ & $\begin{array}{l}\text { CAASP w/ EPD } \\
\text { vs CEA }\end{array}$ & $\begin{array}{l}\text { stroke-free } \\
\text { survival rates; } \\
\text { 30-day death/ } \\
\text { MI/stroke; } \\
\text { restenosis rate; } \\
\text { ipsilat stroke; } \\
\text { cost effectiveness }\end{array}$ & $\begin{array}{l}\text { currently } \sim 300 \text { patients } \\
\text { enrolled in } 18 \text { centers in } 8 \\
\text { countries }\end{array}$ \\
\hline EVA-3S & $\begin{array}{l}\text { Programme } \\
\text { Hospitalier } \\
\text { de Recherche } \\
\text { Clinique, French } \\
\text { Ministry of Health }\end{array}$ & 1000 & $\begin{array}{l}\text { ischemic cerebral or retinal } \\
\text { stroke w/in previous } 4 \text { mos }\end{array}$ & CAASP vs CEA & $\begin{array}{l}\text { 30-day death/MI/ } \\
\text { recurrent stroke; } \\
\text { ipsilat stroke w/in } \\
2-4 \text { yrs }\end{array}$ & $\begin{array}{l}\text { CAASP w/o EPD arm } \\
\text { terminated } 12 / 03 ; \text { study } \\
\text { remains in progress }\end{array}$ \\
\hline
\end{tabular}

* BMBF = Bundesministerium für Bildung und Forschung (German Ministry of Science); CAASP = CA angioplasty and stent placement; CV = cerebrovascular; DFG = Deutsche Forschungsgemeinschaft (German Research Foundation); ICSS = International Carotid Stenting Study; NINDS = National Institute of Neurological Disorders and Stroke; UKSA = United Kingdom Stroke Association;

$\dagger$ Comorbid conditions included age older than 80 years, congestive heart failure, severe chronic obstructive pulmonary disease, previous CEA with recurrent stenosis, previous neck irradiation or radical neck dissection, or high cervical or intrathoracic stenosis.

opened to patients with coexisting conditions that potentially increased the risk posed by CEA, and in whom either a symptomatic CA stenosis of at least $50 \%$ or an asymptomatic stenosis of at least $80 \%$ was identified using duplex ultrasonography. Criteria for high risk included clinically significant cardiac disease (congestive heart failure, abnormal stress test results, or need for open heart surgery), severe pulmonary disease, contralateral CA occlusion, contralateral laryngeal nerve palsy, previous neck surgery or neck radiation therapy, recurrent stenosis after CEA, or age older than 80 years. The primary end point of the study was the cumulative incidence of a major cardiovascular or neurological event at 1 year.

The results of the SAPPHIRE study were recently published in the New England Journal of Medicine. ${ }^{19}$ In this report, 334 patients who met the study criteria were randomized to undergo CA angioplasty and stent placement performed with the aid of an embolic protection device, or they underwent CEA. The follow-up evaluations included repeated neurological examination as well as duplex ultrasonography, followed by digital subtraction angiography in patients in whom ultrasonography studies indicated that $\mathrm{CA}$ restenosis had developed. The trial was terminated early because of an abrupt slowing in the pace of patient enrollment, a phenomenon that the authors attributed to the growing availability of several nonrandomized carotid stent registries; however, the study did reach a statistically significant end point. The primary end point occurred in 20 patients randomly assigned to undergo CA angioplasty and stent placement performed with the aid of an embolic protection device and in 32 patients randomly assigned to undergo CEA. Although the procedure was not demonstrated to be statistically superior to CEA, neither was it found to be inferior in terms of its 1-year cumulative association with stroke, MI, or death. The data also indicated that the periprocedural risks associated with CA angioplasty and stent placement performed with the aid of an embolic protection device in this high-risk population were fewer than those encountered with CEA. These findings held true for both symptomatic and asymptomatic patients.

The SAPPHIRE trial is not without its weaknesses. The difference between the treatment groups in the composite end point at 1 year is related to the greater association of CEA with perioperative MI. Without inclusion of MI as an end point, no statistical difference would be noted between the two groups (the study is not sufficiently powered to detect differences in stroke and death rates between the two groups). As noted in the New England Journal of Medicine editorial accompanying the SAPPHIRE article,${ }^{4}$ the majority of these infarcts were non-Q wave events and perioperative in nature; the importance of late $\mathrm{MI}$ in CEA is perhaps unfairly emphasized in the authors' discussion. Also, a disproportionately larger number of patients (406) were entered into the stent registry than were randomly assigned to treatment (334), with the caveat that patients deemed unfit for surgery were assigned directly to the CA angioplasty and stent placement 
arm. This speaks badly for the surgical environment in which patients in this study were treated. Also, more than $20 \%$ of the patients in each treatment group underwent procedures for recurrent CA stenosis; given the mechanism implicated in CA restenosis after CEA (that is, intimal hyperplasia), the large number of patients with recurrent disease creates an unfair bias toward CA angioplasty and stent placement. Nevertheless, the SAPPHIRE trial has provided evidence that CA angioplasty and stent placement has a significant role in the management of CA disease in symptomatic and asymptomatic patients who have risk factors for high rates of surgeryrelated morbidity or mortality.

\section{CONCLUSIONS}

The role of CA angioplasty and stent placement in the primary and secondary prevention of stroke has continued to evolve with advancements in endovascular technologies and expertise in their use. With improvements in device technology, the safety of this modality has approached that of CEA. In particular, CA angioplasty and stent placement has come under consideration as a firstline therapy in the management of CA stenotic disease in individuals at high risk for complications from surgical intervention. Preliminary data from multiple CA angioplasty and stent placement registries have demonstrated that this modality is an effective means for treating CA stenosis; the SAPPHIRE trial demonstrated that this procedure has a significant role in the management of CA disease in symptomatic and asymptomatic patients who have risk factors for high rates of surgery-related morbidity or mortality.

With the completion of the CREST, the role of CA angioplasty and stent placement in the prevention of stroke in all individuals with significant CA stenosis should be better demarcated. The precise role of this modality in primary and secondary stroke prevention remains to be defined. Intention-to-treat and need-to-treat analyses have still not been documented for CA angioplasty and stent placement in symptomatic or asymptomatic populations. Of concern, the complication rates in older patients enrolled in the SAPPHIRE study were surprisingly high, and because the study did not include an arm in which medical treatment alone was investigated, it is impossible to know whether these patients are better off without a surgical or endovascular intervention. Furthermore, the durability of CA angioplasty and stent placement has not been demonstrated, although rates of posttreatment CA restenosis appear to be comparable to those seen after CEA, with a reported incidence of 4.8 to $8 \%{ }^{6,11}$ Regardless, CA angioplasty and stent placement promises to have a central role in stroke prophylaxis in patients with CA disease.

\section{References}

1. AbuRahma AF, Robinson P, Holt SM, et al: Perioperative and late stroke rates of carotid endarterectomy contralateral to carotid artery occlusion: results from a randomized trial. Stroke 31:1566-1571, 2000

2. ARCHeR Investigators: ARCHeR: Acculink for revascularization of carotids in high-risk patients. Preliminary 30-day results. (http://www.medscape.com/viewarticle/451826) [Accessed 5 January 2005]
3. Ballotta E, Da Giau G, Guerra M: Carotid endarterectomy and contralateral internal carotid artery occlusion: perioperative risks and long-term stroke and survival rates. Surgery 123: 234-240, 1998

4. Cambria RP: Stenting for carotid-artery stenosis. N Engl J Med 351:1565-1567, 2004

5. CAVATAS Investigators: Endovascular versus surgical treatment in patients with carotid stenosis in the Carotid and Vertebral Artery Transluminal Angioplasty Study (CAVATAS): a randomised trial. Lancet 357:1729-1737, 2001

6. Chakhtoura EY, Hobson RW II, Goldstein J, et al: In-stent restenosis after carotid angioplasty-stenting: incidence and management. J Vasc Surg 33:220-226, 2001

7. European Carotid Surgery Trialists' Collaborative Group: Randomised trial of endarterectomy for recently symptomatic carotid stenosis: final results of the MRC European Carotid Surgery Trial (ECST). Lancet 351:1379-1387, 1998

8. Executive Committee for the Asymptomatic Carotid Atherosclerosis Study: Endarterectomy for asymptomatic carotid artery stenosis. JAMA 273:1421-1428, 1995

9. Halliday A, Mansfield A, Marro J, et al: Prevention of disabling and fatal strokes by successful carotid endarterectomy in patients without recent neurological symptoms: randomised controlled trial. Lancet 363:1491-1502, 2004

10. Hsia DC, Moscoe LM, Krushat WM: Epidemiology of carotid endarterectomy among Medicare beneficiaries: 1985-1996 update. Stroke 29:346-350, 1998

11. Lal BK, Hobson RW II, Goldstein J, et al: In-stent recurrent stenosis after carotid artery stenting: life table analysis and clinical relevance. J Vasc Surg 38:1162-1169, 2003

12. Mas JL, Chatellier G, Beyssen B, et al: Carotid angioplasty and stenting with and without cerebral protection: clinical alert from the Endarterectomy Versus Angioplasty in Patients With Symptomatic Severe Carotid Stenosis (EVA-3S) trial. Stroke 35:e18-e20, 2004

13. North American Symptomatic Carotid Endarterectomy Trial Collaborators: Beneficial effect of carotid endarterectomy in symptomatic patients with high-grade carotid stenosis. N Engl J Med 325:445-453, 1991

14. Ohki T, Veith FJ, Grenell S, et al: Initial experience with cerebral protection devices to prevent embolization during carotid artery stenting. J Vasc Surg 36:1175-1185, 2002

15. Sacco RL, Ellenberg JH, Mohr JP, et al: Infarcts of undetermined cause: the NINCDS Stroke Data Bank. Ann Neurol 25: 382-390, 1989

16. Straus SE, Majumdar SR, McAlister FA: New evidence for stroke prevention: scientific review. JAMA 288:1388-1395, 2002

17. van Heesewijk HP, Vos JA, Louwerse ES, et al: New brain lesions at MR imaging after carotid angioplasty and stent placement. Radiology 224:361-365, 2002

18. Wennberg DE, Lucas FL, Birkmeyer JD, et al: Variation in carotid endarterectomy mortality in the Medicare population: trial hospitals, volume, and patient characteristics. JAMA 279: 1278-1281, 1998

19. Yadav JS, Wholey MH, Kuntz RE, et al: Protected carotid-artery stenting versus endarterectomy in high-risk patients. $\mathbf{N}$ Engl J Med 351:1493-1501, 2004

20. Zarins CK: Carotid endarterectomy: the gold standard. J Endovasc Surg 3:10-15, 1996

Manuscript received November 16, 2004.

Accepted in final form December 21, 2004

Address reprint requests to: Bernard R. Bendok, M.D., Department of Neurological Surgery, The Feinberg School of Medicine, Northwestern University, 676 North St. Clair Street, Suite 2210, Chicago, Illinois 60611. email: bbendok@nmff.org. 